\title{
Peroxisome Proliferator-Activated Receptors in Regulation of Cytochromes P450: New Way to Overcome Multidrug Resistance?
}

\author{
Katerina Cizkova, ${ }^{1}$ Anna Konieczna, ${ }^{1}$ Bela Erdosova, ${ }^{1}$ \\ Radka Lichnovska, ${ }^{1}$ and Jiri Ehrmann ${ }^{1,2}$ \\ ${ }^{1}$ Department of Histology and Embryology, Faculty of Medicine and Dentistry, Palacky University, Hnevotinska 3, \\ 77515 Olomouc, Czech Republic \\ ${ }^{2}$ Laboratory of Molecular Pathology, Department of Clinical and Molecular Pathology, Faculty of Medicine and Dentistry, \\ Palacky University, Hnevotinska 3, 77515 Olomouc, Czech Republic
}

Correspondence should be addressed to Katerina Cizkova, keri@email.cz

Received 12 June 2012; Revised 16 August 2012; Accepted 17 September 2012

Academic Editor: Soldano Ferrone

Copyright ( $\odot 2012$ Katerina Cizkova et al. This is an open access article distributed under the Creative Commons Attribution License, which permits unrestricted use, distribution, and reproduction in any medium, provided the original work is properly cited.

Embryonic and tumour cells are able to protect themselves against various harmful compounds. In human pathology, this phenomenon exists in the form of multidrug resistance (MDR) that significantly deteriorates success of anticancer treatment. Cytochromes P450 (CYPs) play one of the key roles in the xenobiotic metabolism. CYP expression could contribute to resistance of cancer cells to chemotherapy. CYP epoxygenases (CYP2C and CYP2J) metabolize about 20\% of clinically important drugs. Besides of drug metabolism, CYP epoxygenases and their metabolites play important role in embryos, normal body function, and tumors. They participate in angiogenesis, mitogenesis, and cell signaling. It was found that CYP epoxygenases are affected by peroxisome proliferator-activated receptor $\alpha(\operatorname{PPAR} \alpha)$. Based on the results of current studies, we assume that PPARs ligands may regulate CYP2C and CYP2J and in some extent they may contribute to overcoming of MDR in patients with different types of tumours.

\section{Introduction}

Embryonic stem cells are equipped with the multiple mechanisms to protect their integrity against potential mutagenic mechanisms associated with inflammation, infection, and dietary toxins. As well as embryo arise from embryonic stem cells, it is supposed that tumours arise from tumour stem cells [1]. Because of similarities between embryonic and tumour cells, it is well accepted that embryonic cells could be used as powerful tool to study natural mechanisms of cell protection. Thus, understanding of protection mechanisms of the cells may help overcome multidrug resistance (MDR) in different types of tumours.

As we described earlier [2], peroxisome proliferatoractivated receptors (PPARs), especially $\operatorname{PPAR} \gamma$, may regulate expression of MDR pumps. It seems that PPARs affect not only the expression of $\mathrm{ABC}$ transporters but they also affect certain enzymes of phase I metabolism of xenobiotics.

$\operatorname{PPAR} \alpha$ and PPAR $\gamma$ ligands have been shown the long history of clinical use as hypolipidemic drugs or for treatment of diabetes $[3,4]$. Thus, we suppose that these compounds may contribute to the safe regulation of MDR in cancer treatment.

\section{Multidrug Resistance and Cytochromes $\mathbf{P 4 5 0}$}

The resistance of cancer cells to chemotherapy is a serious problem in the treatment of patients with different types of tumours. The multidrug resistance is based on resistance of cancer cells to various substances diverging in structure and function. Resistance mechanisms which are utilized by tumour cell to resist cytotoxic drugs are probably developed in normal cell as protection mechanisms 
TABLE 1: Summary of mechanisms of $\operatorname{MDR}[5,6]$.

\begin{tabular}{ll}
\hline Mechanism of MDR & Description \\
\hline Uptake transport of drug & $\begin{array}{l}\text { Decreased expression of uptake transporters (reduced-folate } \\
\text { transporters) and alternation in lipid metabolism modifying } \\
\text { biophysical properties of the lipid bilayer influence drug uptake }\end{array}$ \\
\hline Activation of detoxifying enzymes & Inactivation of drug by phase I and phase II enzymes \\
\hline Drug sequestration & $\begin{array}{l}\text { Drug can be trapped in subcellular organelles such as lysosomes } \\
\text { and endosomes and then extruded from the cell }\end{array}$ \\
\hline Avoiding to drug induced apoptosis & $\begin{array}{l}\text { Occurs mostly via mitochondrial pathway; disruption of balance } \\
\text { between pro-/antiapoptotic factors leads to survival of cancer cells }\end{array}$ \\
\hline Enhanced DNA reparation & $\begin{array}{l}\text { Cells with damaged DNA avoid to senescence, apoptosis, or } \\
\text { necrosis }\end{array}$ \\
\hline Overexpression of membrane transporters & Enhanced drug efflux by ABC transporters \\
\hline Alternation in target molecules & DNA metylation, mutation of topoisomerases I and II \\
\hline Microenvironment & Ph, hypoxia, population of quiescent cells \\
\hline Altered signaling pathways & $\begin{array}{l}\text { Block of apoptosis and expression of genes involved in DNA } \\
\text { reparation and efflux pump }\end{array}$ \\
\hline
\end{tabular}

against environmental cancerogens [1]. Multidrug resistance includes more mechanisms $[5,6]$ (see Table 1$)$.

2.1. Metabolism of Xenobiotics. Detoxification pathways metabolise a number of endogenous and exogenous molecules in three phases. Phase I reaction is catalyzed mainly by members of cytochrome P450 (CYP) superfamily that catalyze redox reactions. CYP-drug interaction leads to several results. These reactions result in detoxification (inactivation) in majority of cases. On the other hand, these enzymes can bioactivate several prodrugs to their active form. Unfortunately, the process can also activate certain harmful compounds (such as potential cancerogens) via transformation into electrophilic species. Both reversible and irreversible inhibitions of CYPs cause harmful drug-drug and drug-food interactions. Phase II of xenobiotic metabolism is a conjugation. Products of phase I are conjugated with molecules such as glutathione or glucuronic acid. During phase III, the conjugated molecule is effluxed out of a cell by specific transporters, especially $\mathrm{ABC}$ transporters $[7,8]$.

Cytochromes P450 (CYPs) are major enzymes in the phase I of the drug metabolism. They metabolise not only various xenobiotics but also a lot of endogenous substrates. Recently, 57 genes have been classified into 18 families and 44 subfamilies according to a degree of homology. Human genome contains also 58 pseudogenes [9]. CYPs are globular hemoproteins consisting of alpha and beta structures. Several of these secondary motifs are roughly coplanar to the prosthetic heme group. CYPs are localized in the mitochondria and the endoplasmic reticulum. Mitochondrial CYPs are involved in the metabolism of endogenous substrates whereas microsomal CYPs metabolise both endogenous and exogenous substrates. The enzymes primary act as monooxygenases. They incorporate one atom of molecular oxygen into the substrate and one into water. These reactions usually change hydrophobic molecule into the polar compound which increases their water solubility. The reaction requires a source of electrons. NADPH cytochrome $\mathrm{P} 450$ reductase in the endoplasmic reticulum and ferredoxin in the mitochondria serve as such a source $[6,7]$.

The presence of active cytochromes P450 in tumours could have negative impact on chemotherapy-mediated cell death because of deactivation of antineoplastic drugs. Cytochromes $\mathrm{P} 450$ responsible for the metabolism of xenobiotic are members of CYP1, CYP2, and CYP3 families. The most important group of enzymes are CYP3A, especially CYP3A4 [7]. Also members of CYP2 family have nonnegligible effect on the drug metabolism. CYP2C subfamily metabolizes about $20 \%$ of clinically important drugs [10]. Antineoplastic drugs which are substrates of CYP2C involve paclitaxel, bexarotene, cyclophosphamide, ifosfamide, imatinib mesylate, idarubicin, tamoxifen, and tretinoin [11]. CYP2J2 also participates in the drug metabolism [12].

On the other hand, different expression of CYPs between the tumour tissue and surrounding normal tissue has potential to be used for patient-specific therapy. It could be used for the development of prodrugs which are nontoxic to normal cells and are activated to the cytotoxic form only in tumours by specific CYP expressed in tumour cell. The preferential expression of certain CYP in tumour could serve as a target for cancer immunotherapy [13].

\section{Cytochrome P450 Epoxygenases}

Enzymes belonging to CYP2C and CYP2J subfamilies are epoxygenases. The human CYP2C subfamily is represented by four highly homologous genes: CYP2C8, 2C9, 2C18, and 2C19 located in an approximate $500-\mathrm{kb}$ cluster on chromosome $10 \mathrm{q} 24$. The CYP2C subfamily represents about $18 \%$ of total adult liver cytochrome P450 content [10]. CYP2C are highly polymorphic. Human CYP2J2 is the only member of CYP2J subfamily. CYP2J2 constitutes about 1-2\% of total cytochromes P450 content in liver. CYP2J2 gene is localized on the short arm on chromosome 1 in locus 1p32.1 [9].

Besides of participation in drug metabolism, epoxygenases have important endogenous function. They convert arachidonic acids to epoxyeicosatrienoic acids (EETs), namely 


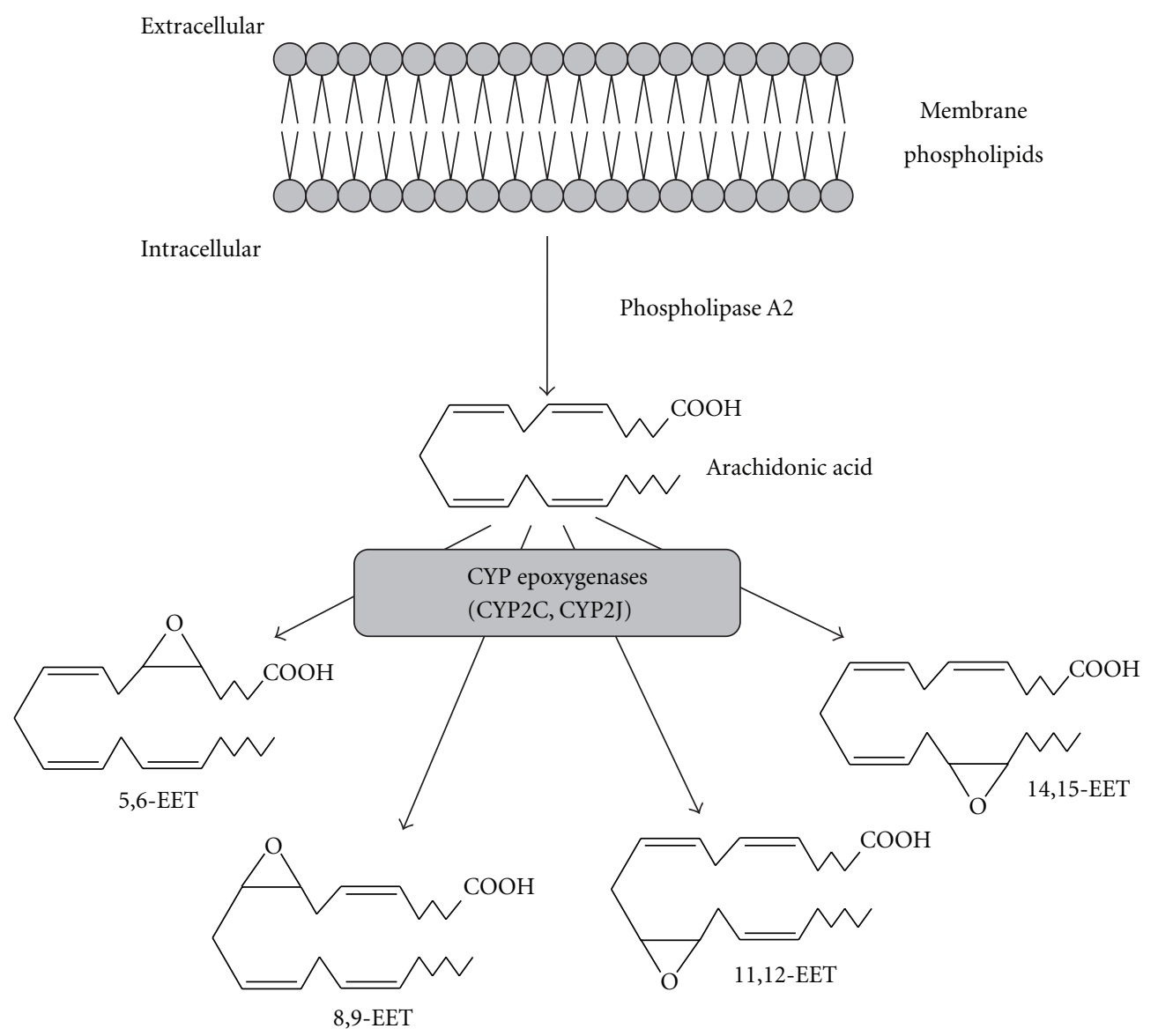

FIgURE 1: Conversion of arachidonic acid to EETs. Arachidonic acid is released from membrane phospholipids by phospholipase A2. CYP epoxygenases (CYP2C and CYP2J) convert AA into four regioisomeric EETs.

5,6-EET, 8,9-EET, 11,12-EET, and 14,15-EET (see Figure 1). These compounds seem to be involved in many biological processes such as inflammation, mitogenesis, cell signaling, regulation of vascular tone, and ion channels. EETs are metabolized mainly by soluble epoxide hydrolase to dihydroxyeicosatrienoic acids (DHETs) which are less active than EETs. Both EETs and DHETs can serve as ligands for peroxisome-proliferator-activated receptors (PPARs) $\alpha$ and $\gamma$ and stimulate PPAR/RXR heterodimer binding to peroxisome proliferator response element (PPRE). The other EET-producing CYPs are CYP4X1 and CYP2U1 but they have minor contribution [14].

Altered EETs production is important for tumour tissue. CYP epoxygenases and their metabolites are involved in angiogenesis which is essential for growth, survival, and metastatic potential of most solid tumours. EETs produced by epoxygenase pathway by CYP2C and CYP2J2 are involved in angiogenesis but this process is not clearly understood. In endothelial cells, EETs are involved in several signaling pathways, including PI3K/Akt, ERK1/2, and Src/STAT-3. It has been shown that 11,12-EET activates sphingosine kinase 1 and thus it causes activation of Akt kinase and transactivation of epidermal growth factor (EGF) receptor [15]. 11,12-EET as well as CYP2C9 overexpression leads to increasing expression of EphB4, the important factor in the vascular development during embryogenesis [16]. Effect of EETs and VEGF on angiogenesis is closely linked. 14,15EET induces VEGF expression and angiogenesis via SrcSTAT-3 [17]. In turn, VEGF stimulates phosphorylation of AMP-activated protein kinase (AMPK). It leads to the induction of CYP2C expression [18]. CYP2C8 and 2C9 expression is induced also by hypoxia. CYP2J2 also promotes metastasis by the upregulation of matrix metallopeptidase9 [19]. Beside angiogenesis, EETs also significantly promote tumour growth by increased proliferation activity through PI3K and MAPK pathway and transactivation of EGFR. EETs also inhibits apoptosis in tumour cell lines [20]. The modulation of immunological response could be another way by which the CYP epoxygenases and their metabolites influence tumours. High level of CYP2J2 in human acute monocytic leukemia cell line may explain high degree of immunosuppression [21].

3.1. CYP2C Expression during Human Embryogenesis; Normal Adult and Tumour Tissues. Expression of CYP2C during human embryogenesis has been investigated in several studies. In the earlier study, Treluyer et al. have examined CYP2C mRNA and protein in foetal livers in age ranging from 16 to 40 weeks of intrauterine development (UID). They detected CYP2C8, 2C9, and 2C18 mRNA at level of approximately 
TABLE 2: Summary of CYP2C and CYP2J2 expression in normal adult tissues. Expression levels estimated at protein and mRNA level [23, 25].

\begin{tabular}{|c|c|c|}
\hline Tissue & CYP protein & CYP mRNA \\
\hline \multicolumn{3}{|c|}{ Gastrointestinal system } \\
\hline Salivary glands & CYP2C8, CYP2C9 & CYP2C8, CYP2C18, CYP2C19, CYP2J2 \\
\hline Stomach & CYP2C9 & \\
\hline Liver & CYP2C9, CYP2J2 & CYP2C8, CYP2C9, СYP2C18, CYP2C19, CYP2J2 \\
\hline Pancreas & CYP2C9, CYP2J2 & \\
\hline Small intestine & CYP2C8, CYP2C9, CYP2J2 & CYP2C8, CYP2C9, CYP2C18, CYP2C19, CYP2J2 \\
\hline Large intestine & CYP2C8, CYP2C9, CYP2J2 & CYP2C8, CYP2C9, CYP2C18, CYP2C19, CYP2J2 \\
\hline \multicolumn{3}{|l|}{ Urinary system } \\
\hline Bladder & & CYP2C8, CYP2C18, CYP2J2 \\
\hline Kidney & CYP2C8, CYP2C9, CYP2J2 & CYP2C8, CYP2C9, CYP2C18, CYP2C19, CYP2J2 \\
\hline \multicolumn{3}{|l|}{ Endocrine system } \\
\hline Adrenals & CYP2C8, CYP2C9 & СYP2C8, CYP2C9, СYP2C18, CYP2C19, CYP2J2 \\
\hline Pituitary gland & CYP2C9, CYP2J2 & CYP2C8, CYP2C9, CYP2C18, CYP2J2 \\
\hline \multicolumn{3}{|l|}{ Cardiovascular system } \\
\hline Myocardium & CYP2C9, CYP2J2 & CYP2C8, CYP2J2 \\
\hline \multicolumn{3}{|l|}{ Lymphoid tissues } \\
\hline Tonsils & CYP2C8, CYP2C9 & \\
\hline Spleen & CYP2C9 & CYP2C8, CYP2C9, CYP2C18, CYP2C19, CYP2J2 \\
\hline Lymphatic nodes & CYP2C9 & \\
\hline Thymus & & CYP2C8, CYP2C9, CYP2C18, CYP2C19, CYP2J2 \\
\hline \multicolumn{3}{|l|}{ Respiratory system } \\
\hline Trachea & & CYP2C8, CYP2C9, СYP2C18, CYP2C19, CYP2J2 \\
\hline Lung & CYP2C9, CYP2J2 & CYP2C8, CYP2C9, CYP2C18, CYP2C19, CYP2J2 \\
\hline \multicolumn{3}{|l|}{ Skin } \\
\hline Epidermis & CYP2C9 & \\
\hline Mammary gland & & CYP2C8, CYP2C9, СYP2C18, CYP2C19, CYP2J2 \\
\hline \multicolumn{3}{|l|}{ Reproductive system } \\
\hline Endometrium & CYP2C9 & \\
\hline Ovary & & CYP2C8, CYP2C9, CYP2C18, CYP2C19, CYP2J2 \\
\hline uterus & & CYP2C8, CYP2C9, CYP2C18, CYP2C19, CYP2J2 \\
\hline placenta & & CYP2C8, CYP2C9, CYP2C18, CYP2C19, CYP2J2 \\
\hline prostate & & CYP2C8, CYP2C9, CYP2C18, CYP2C19, CYP2J2 \\
\hline testes & & CYP2C8, CYP2C9, CYP2C18, CYP2C19, CYP2J2 \\
\hline \multicolumn{3}{|c|}{ Musculoskeletal system } \\
\hline bone marrow & & CYP2C8, CYP2C18, CYP2J2 \\
\hline skeleton muscle & & СYP2C8, СYP2C9, СYP2C18, CYP2C19, СYP2J2 \\
\hline
\end{tabular}

$10 \%$ of adult levels but proteins and protein activities were undetectable which suggests possible posttranscriptional control mechanisms [22].

More recently, CYP2C9 protein was detected in foetal liver between 8 to 24 weeks of gestation in lower levels than in adults (about 1-2\%). CYP2C9 expression increases with the foetal age and it reaches approximately $30 \%$ of mature value in the third trimester. CYP2C19 protein was also detected as early as 8 weeks IUD but protein level is similar in all gestational ages. Measurement of enzyme activities shows similar pattern as protein analysis. Contrary to the adult liver, CYP2C19 protein level is higher than CYP2C9 in the foetal liver [10]. Bieche et al. have also confirmed expression of CYP2C8, CYP2C9, CYP2C18, and CYP2C19 mRNA in foetal liver [25].

CYP2C proteins are expressed also in various adult healthy and tumour tissues. Enayetallah et al. detected human epoxygenases CYP2C8 and 2C9 in different tissues by immunohistochemistry [23]. CYP expression in different human tissues at mRNA level was analyzed by Bieche et al. [25]. Their results are summarized in Table 2. CYP2C enzymes are mainly hepatic proteins [25]. Expression of different CYPs mRNAs in the lung tissue has been studied by Leclerc and coworkers. Moderate expression level of CYP2C9 and 2C18 and low level of CYP2C8 and 2C19 were detected in the bronchial mucosa. Low levels of CYP2C were detected in parenchymal cells [24].

In comparison to the normal tissue, there are differences in CYP2C expression pattern in tumour tissue. Enayetallah et al. proved CYP2C8 and 2C9 protein expression in different human neoplasms by immunohistochemistry. Positive immunostaining for CYP2C9 was detected in cholangiocarcinoma, stomach, and lung adenocarcinomas, breast carcinoma, squamous cell carcinoma of mouth, tongue, 
larynx, and pharynx. CYP2C8 and CYP2C9 proteins were detected in prostate adenocarcinoma. CYP2C8 and 2C9 epoxygenases were also detected in endometrial carcinoma. Basal skin cell carcinoma was positive only for CYP2C9 [23]. Expression of CYP2C8 occurs also in the majority of ovarian tumour regardless of histological type, stage, or grade [26]. Lower expression of CYP2C mRNA in comparison to normal tissue was detected in squamous cell carcinoma of lung [24].

\subsection{CYP2J2 Expression during Human Embryogenesis: Nor-} mal Adult and Tumour Tissues. Expression of CYP2J2 during human embryogenesis has been also investigated. The expression of CYP2J2 has been studied in the liver [25, 27] and extrahepatic tissues. CYP2J2 mRNA has been detected in the foetal liver as early as in 11-week-old foetus. The highest expression of CYP2J2 was detected in foetal liver and heart at comparable levels. CYP2J2 transcripts can be also detected in intestines, lungs, kidneys, adrenals, testes, and brain but in lower levels than in the liver. Only small interindividual variability was observed in mRNA level whereas differences are more obvious at the protein level [27]. CYP2J2 mRNA is also strongly expressed in placenta [25].

Expression of CYP2J2 in various normal adult tissues at protein [23] and mRNA levels [25] is summarized in Table 2. In contrast to CYP2C expression, which is mainly hepatic, CYP2J2 expression was detected predominantly in extrahepatic tissues [25].

Increased CYP2J2 expression was detected in the most of esophageal, pulmonary, breast, stomach, liver, and colon carcinomas in comparison with adjacent normal tissue and also in tumour cell lines [28]; it was also detected in endometrial carcinoma, cholangiocarcinoma, and squamous cell carcinomas of tongue, pharynx, and larynx [29]. Unlike Jiang et al. [28], Enayetallah et al. [29] detected lower level of CYP2J2 expression in liver and kidney carcinomas in comparison with surrounding healthy tissue. Interestingly, CYP2J2 protein was undetectable in prostate and pancreatic adenocarcinomas. CYP2J2 expression was detected only in some squamous cell carcinomas of lungs and small part of lung adenocarcinomas [29]. The discrepancy remains unclear. Leclerc et al. detected increased CYP2J2 expression in lung adenocarcinomas but CYP2J2 mRNA was underexpressed in squamous cell carcinoma of lungs [24]. Increased expression of CYP2J2 was detected also in ovarian tumour [30]. Recently, highly selective expression of CYP2J2 was detected in hematological malignant diseases [31].

\section{Peroxisome Proliferator-Activated Receptors (PPARs)}

As we mentioned above, PPARs, especially $\operatorname{PPAR} \alpha$, play a role in the regulation of certain enzymes of phase I metabolism of xenobiotics. Therefore, they could contribute to the multidrug resistance of tumours.

The PPARs belong to nuclear receptors superfamily. PPARs are ligand-dependent transcriptional factors as well as steroid, thyroid, and retinoid receptors. PPAR ligands are both endogenous and exogenous compounds [32] (see Table 3). PPARs receptors consist of three members: PPAR $\alpha$, $\operatorname{PPAR} \beta / \delta$, and PPAR $\gamma$ encoded by different genes. PPAR $\gamma$ gene contains three different promoters which give rise to three different mRNA transcripts: PPAR $\gamma 1$, PPAR $\gamma 2$, and PPAR $\gamma 3$. PPAR $\gamma 1$ and PPAR $\gamma 3$ are translated to the identical protein PPAR $\gamma 1$. Moreover, Chen et al. described additional three mRNA transcripts of PPAR $y$ in human THP- 1 macrophages: PPAR $\gamma 4$, PPAR $\gamma 5$, and PPAR $\gamma 7$. Only PPAR $\gamma 4$ encodes novel protein isoform; PPAR $\gamma 4$. PPAR $\gamma 5$, and PPAR $\gamma 7$ are translated to protein PPAR $\gamma 1$ [33]. Each of PPARs has different ligand, target genes, and biological role. The expression of PPARs varies widely among tissues. PPAR $\alpha$ is highly expressed in cells with active fatty acid oxidation including hepatocytes, cardiomyocytes, enterocytes, and proximal tubuli of kidneys. PPAR $\beta / \delta$ is expressed ubiquitously and often in higher level than PPAR $\alpha$ and PPAR $\gamma$. PPAR $y$ is expressed mainly in adipose tissue (PPAR $y 2$ ) and immune system (PPAR $\gamma 1)$. PPARs are important for various biological processes such as energetic homeostasis, development, differentiation, apoptosis, neoplastic transformation, inflammatory response, and tissue regeneration. They are involved in chronic diseases such as diabetes, obesity, and atherosclerosis [34].

PPARs bind to the peroxisome proliferator response element (PPRE) in the promoter of target genes as heterodimer with retinoid X receptor (RXR). Besides ligands, PPARs interact with a lot of coregulator proteins. Coactivators such as PPAR binding protein (PBP), SRC-1, p300, CBP, PGC$1 \alpha$ ) stimulate PPAR target genes expression and corepressors; for example, SMRT and N-CoR inhibit expression of target genes. PPAR $\alpha$ and to a lesser extend PPAR $\beta / \delta$ are associated with the heat shock protein complexes $[32,34]$.

Similar to other nuclear receptors, PPARs are phosphoproteins. Therefore, their transcriptional activity can be also affected by crosstalk between phosphorylation and dephosphorylation. The effect of phosphorylation depends on cellular context, receptor subtype, and residue metabolised. For example, MAPK pathway activates PPAR $\alpha$ in hepatocytes, whereas it inhibits PPAR $\gamma$ activity in adipocytes [35].

4.1. PPARs Expression during Prenatal Development. PPARs play an important role in the development of germ cells and embryos. Each of three PPARs isoforms are expressed in somatic and germ cells of testes and ovaries, PPAR $\gamma$ more than others [36]. It has been known that $\operatorname{PPAR} \beta / \delta$ and PPAR $y$ are necessary for implantation and survival of the early embryo. PPAR $\gamma$ and $\operatorname{PPAR} \beta / \delta$ are highly expressed in mouse placenta but functional redundancies or compensations between them are not fully operative [37]. The homozygous disruption of PPAR $y$ results in the death of 10-day-old embryo. PPAR $\gamma$ null mice embryos have showed abnormal development of the foetal and maternal vascular network in placenta, severe myocardial thinning, and overall growth retardation $[38,39]$. Similarly, the most (but not all) $\operatorname{PPAR} \beta / \delta$ null mice embryos died at age of 10 days due to placenta failure. PPAR $\beta / \delta$ promotes differentiation of 
TABLE 3: Overview of PPARs endogenous and exogenous ligands according to [32].

\begin{tabular}{|c|c|c|}
\hline & endogenous ligands & exogenous ligand \\
\hline \multirow{17}{*}{$\operatorname{PPAR} \alpha$} & $\begin{array}{l}\text { Unsaturated fatty acids (oleic, palmitoleic, linoleic, } \\
\text { arachidonic acid) }\end{array}$ & $\begin{array}{l}\text { Hypolipidemic drugs (bezafibrate, clofibrate, ciprofibrate, fenofibrate, } \\
\text { gemfibrozil, nafenopin, WY-14643) }\end{array}$ \\
\hline & Saturated fatty acids (palmitoic and stearic acid) & Phytanic acid \\
\hline & $5,6-, 8,9-, 11,12-, 14,15$-eet & Nsaids (indomethacin) \\
\hline & Hydroperoxyeicosatetraenoic acids (hetes) & Dehydroxyepiandrosterone (DHEA) \\
\hline & $20,14,15$-heet & Phtalates \\
\hline & Prostaglandins (PGD2, PGD1) & Anticonvulsants (valproic acid, phenobarbital) \\
\hline & Leucotriene B4 (LTB4) & Telmisartan \\
\hline & Vldl & Phytol \\
\hline & & Perfluorinated alkyl and sulfonyl acid comp. (pfoa, pfna, pfos) \\
\hline & & Oxirane compounds \\
\hline & & Etya \\
\hline & & Epoxyisoprostane \\
\hline & & Drf-2519 \\
\hline & & Bm 17.0744 \\
\hline & & Benz[a]anthracene \\
\hline & & Di- and trichloroacetic acid \\
\hline & & Mk- $886^{*}$ \\
\hline \multirow{7}{*}{$\operatorname{PPAR} \beta$} & Mono-and polyunsaturated fatty acids & Tetradecylthioacetic acid \\
\hline & Saturated fatty acids & Hypolipidemic drugs (WY-14643, bezafibrate) \\
\hline & Prostaglandins (PGA1, PGD1, PGD2) & Valproic acid \\
\hline & 13-S-hydroxyoctadecadienoic acid (13-S-HODE) & Benz[a]anthracene \\
\hline & 4-hydroxynonenol (4-HNE) & Treprostinil sodium \\
\hline & VLDL, oxldl & Gw-501516 \\
\hline & & Sulindac sulfide* \\
\hline \multirow{19}{*}{$\operatorname{PPAR} \gamma$} & $\begin{array}{l}\text { Unsaturated fatty acids (linoleic, linolenic, } \\
\text { arachidonic, eisosapentateonic acid) }\end{array}$ & $\begin{array}{l}\text { Thiazolidinediones (e.g., ciglitazone, pioglitazone, rosiglitazone, } \\
\text { troglitazone) }\end{array}$ \\
\hline & $\begin{array}{l}\text { 9-s-hode, 13-s-hode } \\
\text { 15-s-hete, } 5 \text {-s-hete, 12-s-hete }\end{array}$ & $\begin{array}{l}\text { Nsaids (indomethacin, diclofenac, oxaprozin, zaltoprofen, ibuprofen, } \\
\text { nimesulide, sulindac sulfide*) } \\
\text { Hypolipidemic drugs (bezafibrate, WY-14643, atorvastin) }\end{array}$ \\
\hline & Lysophosphatidic acid & Phtalates (MEHD, DEPH) \\
\hline & Hexadecylazelaicphosphatidylcholine & Bisphenol A diglicidyl ether \\
\hline & Prostaglandins (PGD1, PGD2, PGA1) & Natural (plant) phenols (genistein, curcumin, resveratol) \\
\hline & Nitroalkane derivate of linoleic acid & Telmisartan \\
\hline & Oxldl & Jtp-426467 \\
\hline & & Pemoline \\
\hline & & Phenylacetate \\
\hline & & Dhea \\
\hline & & LY171883 \\
\hline & & 2-bromopalmitate \\
\hline & & $\begin{array}{l}\text { antidiabetic drugs (glimepiride, tolbutamide, chlorpropamide, } \\
\text { gliclazide, glibenclamide, SR-202) }\end{array}$ \\
\hline & & F-L-Leu \\
\hline & & abietic acid \\
\hline & & organotin compounds tributyl- and triphenyltin \\
\hline & & perfluorooctanic acid (PFOA) \\
\hline & & T0070907* \\
\hline & & GW9662* \\
\hline
\end{tabular}




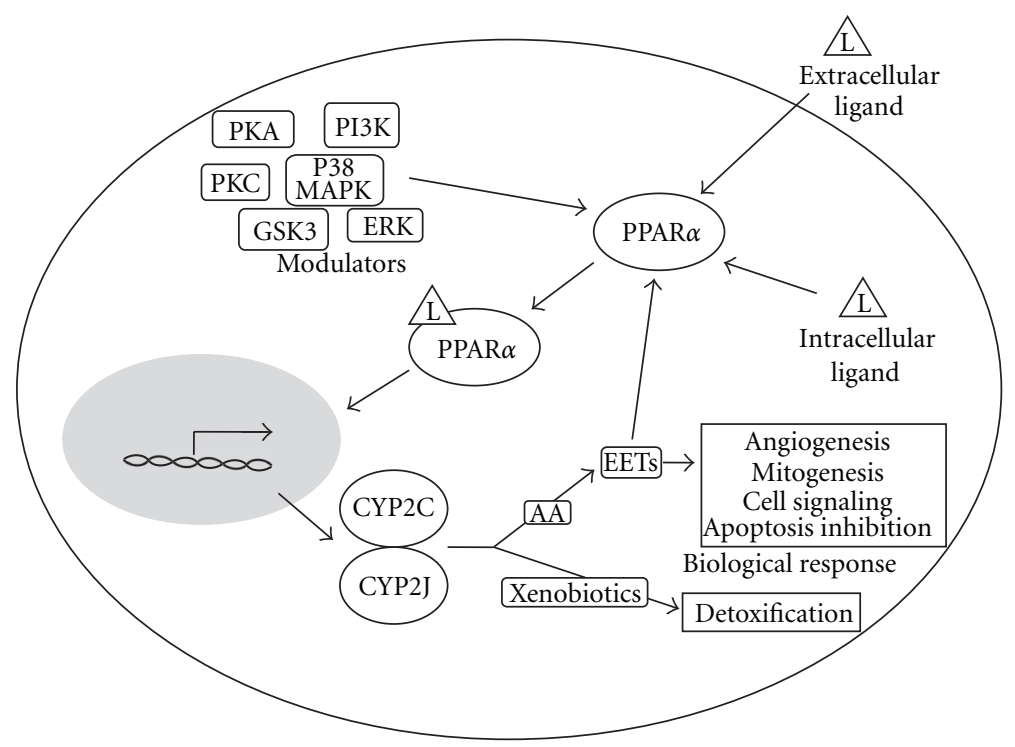

Figure 2: Our proposed model of PPAR $\alpha$ effect on CYP2C and CYP2J (simplified): activation of PPAR $\alpha$ results in CYP2C and CYP2J expression. CYP2C and CYP2J convert arachidonic acid (AA) to EETs, which have cytoprotective function and also can serve as PPAR $\alpha$ ligand, resulting in feedback mechanism. CYP2C and CYP2J also metabolise xenobiotics.

giant cells. Both PPAR $\gamma$ and $\operatorname{PPAR} \beta / \delta$ are also required for accumulation of lipid droplets in placenta $[37,38]$.

Rodent experiments also have showed that PPAR $\alpha$ participates on later skin development [40]. PPAR $\beta / \delta$ plays a role in the development of skin, hair follicles [40], muscles [36], and nervous system [41]. Similar to PPAR $\beta / \delta$, PPAR $\gamma$ also has an influence on developing nervous system [41] and muscles [36]. PPAR $\beta / \delta$ and $\operatorname{PPAR} \gamma$ together play a role in adipose tissue differentiation.

There is few information about PPARs expression in human prenatal development. Huin et al. have investigated expression of PPARs in gastrointestinal tract in human foetuses from 7 to 22 weeks of IUD by immunohistochemistry. Every three isoforms of PPARs have been detected as early as in 7-week-old foetus. With the exception of stomach, PPAR $\gamma$ is the predominant isoform in digestive tract [42]. PPAR $\gamma$ is also highly expressed in human placenta, where it is important for differentiation and function of trophoblast [43].

More recently, expression of PPARs isoforms in the foetal development has been investigated by Abott et al. [44]. They focused on mRNA and protein levels of PPARs in foetuses from days 54 to 125 in different foetal tissues by qPCR and western blotting. They investigate mRNA and protein levels in foetal heart, lung, stomach, liver, intestine, adrenal, kidneys, spleen, and thymus. Their results were consistent with Huin for intestine, but discrepancies were detected in stomach [44].

\section{Relationship between CYPs and PPARs}

Although PPARs have been considered biological sensors of lipid metabolism, it has been shown that PPAR $\alpha$ regulates also various genes involved in the biotransformation. PPAR $\alpha$ directs transcription of CYP4 which is important for metabolism of biologically important compounds such as fatty acids. In human hepatocytes, PPAR $\alpha$ activates members of CYP1A, CYP2A, CYP2B, CYP2C, CYP2E, CYP2J, and CYP3A subfamilies and some conjugating enzymes (e.g., EPHX2, GSTA, and UGT1A9) [45]. Our proposed model of influence of PPAR $\alpha$ on CYP2C and CYP2J is shown in Figure 2. PPAR $\alpha$ participates with other nuclear receptors in the regulation of other xenobiotic metabolizing enzymes, such as PXR, CAR, and FXR [8].

5.1. In Vivo and In Vitro Animal Studies. Even if animal models are very useful tool for in vitro and in vivo studies, differences between rodent and human xenobiotic metabolism are known. PPAR $\alpha$ ligand affects CYP2C in both human and rodent but in quite different ways.

In murine liver, PPAR $\alpha$ causes downregulation of some genes involved in phase I of biotransformation, including CYP2C11, CYP2C12, and CYP2C29 [45].

EMD 392949 is a ligand for both, PPAR $\alpha$ and PPAR $\gamma$. The oral treatment of male cynomolgus monkey for 4 weeks leads to the increase CYP2C9 expression and stronger induction was observed after longer term exposition. Changes in gene expression were reversed after recovery period. In vitro, EMD 392949 suppresses CYP2C expression in rat hepatocytes, as well as fenofibrate treatment [46].

Another PPAR $\alpha$ agonist is clofibric acid. Male Wistar rats were treated for 3 days orally by clofibric acid. It led to downregulation of CYP2C11. Liver CYP2C11 expression is regulated by the growth hormone via Janus kinase/signal transducer and activators of transcription proteins (JAK/STAT5b). PPAR $\alpha$ downregulates STAT5b transcriptional activity [47].

PPAR $\alpha$ agonist fenofibrate causes downregulation of CYP2C11 mRNA and protein in liver of male Wistar rats and male hypertriglyceridemic rats after 20 days of fenofibrate-containing diet. CYP2C6 mRNA and protein was downregulated too, but in lesser extend [48]. Fenofibrate also 
affects CYP2C23 expression in kidneys of Zucker diabetic fatty rats. 26-week-old male ZDF rats were fed by fenofibrate for 6 weeks. The treatment results in the significant increase of CYP2C23 protein production in both renal microvessels and kidney cortex [49].

Rodent epoxygenases (as well as human enzymes) and their metabolites have proangiogenic function. Experiments with CYP2C44 knockout mice prove that murine CYP2C44 (catalytic homolog of human CYP2C8 and 2C9) is a target gene for PPAR $\alpha$. WY-14643, PPAR $\alpha$ ligand, reduces EETs synthesis by downregulation of CYP2C44 and leads to marked reduction of tumour mass, volume, and vascularization of xenograft tumours. This process is PPAR $\alpha$ dependent. The same results were obtained from mouse with human PPAR $\alpha$ gene $[3,50]$.

While in human CYP2J2 is only one member of CYP2J family, in the mouse up to 8 putative homologues (CYP2J5CYP2J13) exist. This investigation of the role of endogenous epoxygenases in the mouse is difficult. It is possible to use fasting as a model of PPAR $\alpha$ activation. In vivo, in cardiacspecific CYP2J2 transgenic mice, fasting selectively augments the expression of pyruvate dehydrogenase kinase 4 (PDK4), a target PPAR $\alpha$ gene which is selectively induced by PPAR $\alpha$ ligand in the cardiac tissue [51].

5.2. In Vitro Studies with Human Cells. EETs produced from arachidonic acid by CYP2C and 2J2 are able to activate $\operatorname{PPAR} \alpha$ in human HepG 2 cell line. In turn, $\operatorname{PPAR} \alpha$ regulates expression of enzymes responsible for EETs formation resulting in the feedback mechanism [52]. Activation of PPARs, particularly PPAR $\alpha$, by CYP2J2 products was also confirmed in HEK293 cell line by Wray et al. [51]. Their results have shown that 8,9-EET and 11,12-EET, but not 14,15EET, activated PPAR $\alpha$. CYP2J2 and CYP2C8 epoxygenases products play the important role also in the immunological response. The epoxygenases regulate monocyte/macrophage activation depending on the underlying activation state. Products of epoxygenases in monocyte/macrophage act as the anti-inflammatory tool, at least in part by producing PPAR $\alpha$ ligands [21].

Prueksaritanont et al. have investigated effect of clofibric and fenofibric acids and gemfibrozil (PPAR $\alpha$ ligands) on human hepatocytes. All three fibrates elevate CYP2C8 mRNA level. Clofibric and fenofibric acids also increase CYP2C8 activity. On the other hand, treatment by gemfibrozil leads to the reduction of CYP2C8 activity [53]. In contrast to rat hepatocytes, treatment of human hepatocytes by EMD 392949 causes strong induction of CYP2C8 [46].

Human CYP2C enzymes are affected also by thiazolidinediones, PPAR $\gamma$ agonists. Troglitazone causes inhibition of CYP2C8, 2C9, and 2C19. Pioglitazone has also potential to inhibit CYP2C8 [4].

\section{Discussion}

Despite of the huge progress in cancer diagnosis and treatment, development of multidrug resistance in patients with tumour remains the serious problem. Normal cells have different mechanisms to protect themselves against external noxious substances or toxic products of their metabolism. Cancer cells utilize these mechanisms in the protection of anticancer drugs.

CYP epoxygenases, CYP2C, and CYP2J play nonnegligible role in tumors. These enzymes metabolise about $20 \%$ of clinically used drugs [10]; moreover, they play a role in angiogenesis [15-18], cell migration, metastasis [19], and immunological response [51]. According to in vitro and in vivo studies mentioned above, we hypothesize that PPAR $\alpha$ ligands affect CYP2C and CYP2J. Moreover, products of CYP2C and CYP2J metabolism of arachidonic acid, EETs, are able to act as PPAR $\alpha$ ligands. It results in feedback mechanism $[51,52]$. Cytoprotective EETs increase proliferation and cell migration and also inhibit apoptosis [20].

PPAR $\alpha$ ligands are used in the treatment of lipid disorders and plasma dyslipidemia. These drugs have the long history of clinical use. They seem to be well tolerated to have low toxicity and have limited side effects [50]. Regulation of CYP2C and/or CYP2J expression in tumour overexpressing these proteins could increase efficacy of anticancer drugs (which are inactivated by CYP2C and CYP2J). Moreover, the angiogenesis could be reduced. Regulation of CYP epoxygenases in monocyte/macrophage could force immunological response. Moreover, the decreased expression of CYP2C and CYP2J in monocytes may lead to the stronger immunological response. Finally, regulation of cytoprotective EETs production may result in reduced proliferation and migration and enhanced apoptosis of tumour cells. All these mechanisms may contribute to better cancer treatment and reduction of multidrug resistance.

\section{Conclusion}

In conclusion, we assume that detailed investigation of regulation of CYP2C and CYP2J by PPAR $\alpha$ provides valuable information which could be useful to overcome multidrug resistance in patients with different types of tumours.

\section{Abbreviations}

$\begin{array}{ll}\text { MDR: } & \text { Multidrug resistance } \\ \text { PPAR: } & \text { Peroxisome proliferator-activated } \\ & \text { receptor }\end{array}$

ABC transporter: ATP binding cassette transporter

CYP: $\quad$ Cytochrome P450

NADPH: Nicotinamide adenine dinucleotide

$\begin{array}{ll} & \text { phosphate } \\ \text { EET: } & \text { Epoxyeicosatrienoic acid }\end{array}$

DHET: Dihydroxyeicosatrienoic acid

RXR: $\quad$ Retinoid X receptor

PPRE: $\quad$ Peroxisome proliferator response

IUD: Intrauterine development

PI3K: $\quad$ Phosphoinositide 3-kinase

ERK: $\quad$ Extracellular signal-regulated kinase

STAT: $\quad$ Signal Transducers and Activators of Transcription 


$\begin{array}{ll}\text { EGF: } & \text { Epidermal growth factor } \\ \text { EphB4: } & \text { Ephrin type-B receptor } 4 \\ \text { VEFG: } & \text { Vascular endothelial growth factor } \\ \text { MAPK: } & \text { Mitogen-activated protein kinase } \\ \text { EGFR: } & \text { Epidermal growth factor receptor } \\ \text { PBP: } & \text { PPAR binding protein } \\ \text { CBP: } & \text { CREB-binding protein } \\ \text { PGC-1 } \alpha: & \text { PPAR } \gamma \text { coactivator } 1 \alpha \\ \text { SRC-1: } & \text { Steroid receptor coactivator 1 } \\ \text { SMRT: } & \text { Silencing mediator for retinoid and } \\ & \text { thyroid hormone receptor } \\ \text { N-CoR: } & \text { Nuclear receptor corepressor } \\ \text { EPHX2: } & \text { Epoxide hydrolase } 2 \\ \text { GSTA: } & \text { Glutathione s transferase A } \\ \text { UGT1A9: } & \text { UDP-glucuronosyltransferase 1A9 } \\ \text { PXR: } & \text { Pregnane X receptor } \\ \text { CAR: } & \text { Constitutive androstane receptor } \\ \text { FXR: } & \text { Farnesoid X receptor } \\ \text { JAK: } & \text { Janus kinase } \\ \text { PDK4: } & \text { Pyruvate dehydrogenase kinase } 4 \\ \text { HETE: } & \text { Hydroperoxyeicosatetraenoic acid } \\ \text { HEET: } & \text { Hydroepoxyeicosatrienoic acid } \\ \text { PGD1(D2, A1): Prostaglandin D1 (D2, A1) } \\ \text { HODE: } & \text { Hydroxyoctadecadienoic acid } \\ \text { VLDL: } & \text { Very low-density lipoprotein } \\ \text { OxLDL: } & \text { Oxidized low-density lipoprotein } \\ \text { NSAID: } & \text { Nonsteroidal anti-inflammatory drug } \\ \text { DHEA: } & \text { Dehydroeepiandrosteron } \\ \text { PFOA: } & \text { Perfluorooctanoic acid } \\ \text { PFNA: } & \text { Perfluorononanoic acid } \\ \text { PFOS: } & \text { Perfluorooctane sulfonate } \\ \text { ETYA: } & \text { Eicosatetraynoic acid } \\ \text { MEHP: } & \text { Mono-2-ethylhexyl phtalate } \\ \text { DEHP: } & \text { Di-2-ethylhexyl phtalate. } \\ & \end{array}$

\section{Acknowledgments}

This study was supported by LF_2011_009 and CZ.1.05/ 2.1.00/01.0030.

\section{References}

[1] B. C. Baugley, "Multidrug resistance in cancer," in Multidrug Resistance in Cancer (Methods in Molecular Biology), J. Zhou, Ed., pp. 1-14, Humana Press, New York, NY, USA, 2010.

[2] A. Konieczna, R. Lichnovka, B. Erdosova, and J. Ehrmann, "The role of PPARs in MDR - a lesson from embryonic development," Neoplasma, vol. 56, no. 4, pp. 279-283, 2009.

[3] A. Pozzi, V. Popescu, S. Yang et al., "The anti-tumorigenic properties of peroxisomal proliferator-activated receptor $\alpha$ are arachidonic acid epoxygenase-mediated," The Journal of Biological Chemistry, vol. 285, no. 17, pp. 12840-12850, 2010.

[4] J. Sahi, C. B. Black, G. A. Hamilton et al., "Comparative effects of thiazolidinediones on in vitro P450 enzyme induction and inhibition," Drug Metabolism and Disposition, vol. 31, no. 4, pp. 439-446, 2003.

[5] H. R. Mellor and R. Callaghan, "Resistance to chemotherapy in cancer: a complex and integrated cellular response," Pharmacology, vol. 81, no. 4, pp. 275-300, 2008.
[6] J. P. Gillet and M. M. Gottesman, "Mechanisms of multidrug resistance in cancer," in Multidrug Resistance in Cancer (Methods in Molecular Biology), J. Zhou, Ed., pp. 47-76, Humana Press, New York, NY, USA, 2010.

[7] C. M. Brown, B. Reisfeld, and A. N. Mayeno, "Cytochromes P450: a structure-based summary of biotransformations using representative substrates," Drug Metabolism Reviews, vol. 40, no. 1, pp. 1-100, 2008.

[8] O. Barbier, C. Fontaine, J. C. Fruchart, and B. Staels, "Genomic and non-genomic interactions of $\operatorname{PPAR} \alpha$ with xenobioticmetabolizing enzymes," Trends in Endocrinology and Metabolism, vol. 15, no. 7, pp. 324-330, 2004.

[9] D. R. Nelson, "The cytochrome P450 homepage," Human Genomics, vol. 4, no. 1, pp. 59-65, 2009.

[10] S. B. Koukouritaki, J. R. Manro, S. A. Marsh et al., "Developmental expression of human hepatic CYP2C9 and CYP2C19," Journal of Pharmacology and Experimental Therapeutics, vol. 308, no. 3, pp. 965-974, 2004.

[11] C. D. Scripture, A. Sparreboom, and W. D. Figg, "Modulation of cytochrome $\mathrm{P} 450$ activity: implications for cancer therapy," The Lancet Oncology, vol. 6, no. 10, pp. 780-789, 2005.

[12] C. A. Lee, D. Neul, A. Clouser-Roche et al., "Identification of novel substrates for human cytochrome P450 2J2," Drug Metabolism and Disposition, vol. 38, no. 2, pp. 347-356, 2010.

[13] M. C. E. McFadyen, W. T. Melvin, and G. I. Murray, "Cytochrome P450 enzymes: novel options for cancer therapeutics," Molecular Cancer Therapeutics, vol. 3, no. 3, pp. 363-371, 2004.

[14] D. Panigrahy, A. Kaipainen, E. R. Greene, and S. Huang, "Cytochrome P450-derived eicosanoids: the neglected pathway in cancer," Cancer Metastasis Reviews, vol. 29, no. 4, pp. 723-735, 2010.

[15] G. Yan, S. Chen, B. You, and J. Sun, "Activation of sphingosine kinase-1 mediates induction of endothelial cell proliferation and angiogenesis by epoxyeicosatrienoic acids," Cardiovascular Research, vol. 78, no. 2, pp. 308-314, 2008.

[16] A. C. Webler, R. Popp, T. Korff et al., "Cytochrome P450 2C9indiiced angiogenesis is dependent on EphB4," Arteriosclerosis, Thrombosis, and Vascular Biology, vol. 28, no. 6, pp. 11231129, 2008.

[17] S. Y. Cheranov, M. Karpurapu, D. Wang, B. Zhang, R. C. Venema, and G. N. Rao, "An essential role for SRC-activated STAT3 in 14, 15-EET-induced VEGF expression and angiogenesis," Blood, vol. 111, no. 12, pp. 5581-5591, 2008.

[18] A. C. Webler, U. R. Michaelis, R. Popp et al., "Epoxyeicosatrienoic acids are part of the VEGF-activated signaling cascade leading to angiogenesis," American Journal of Physiology, vol. 295, no. 5, pp. C1292-C1301, 2008.

[19] J. G. Jiang, Y. G. Ning, C. Chen et al., "Cytochrome P450 epoxygenase promotes human cancer metastasis," Cancer Research, vol. 67, no. 14, pp. 6665-6674, 2007.

[20] G. F. Shen, J. G. Jiang, X. N. Fu, and D. W. Wang, "Promotive effects of epoxyeicosatrienoic acids (EETs) on proliferation of tumor cells," Chinese Journal of Cancer, vol. 27, no. 11, pp. 1130-1136, 2008.

[21] J. Bystrom, J. A. Wray, M. C. Sugden et al., "Endogenous epoxygenases are modulators of monocyte/macrophage activity," PLoS ONE, vol. 6, no. 10, Article ID e26591, 2011.

[22] J. M. Treluyer, G. Gueret, G. Cheron, M. Sonnier, and T. Cresteil, "Developmental expression of CYP2C and CYP2Cdependent activities in the human liver: in-vivo/in-vitro correlation and inducibility," Pharmacogenetics, vol. 7, no. 6, pp. 441-452, 1997. 
[23] A. E. Enayetallah, R. A. French, M. S. Thibodeau, and D. F. Grant, "Distribution of soluble epoxide hydrolase and of cytochrome P450 2C8, 2C9, and 2J2 in human tissues," Journal of Histochemistry and Cytochemistry, vol. 52, no. 4, pp. 447454, 2004.

[24] J. Leclerc, G. Tournel, E. C. N. Ngangue et al., "Profiling gene expression of whole cytochrome P450 superfamily in human bronchial and peripheral lung tissues: differential expression in non-small cell lung cancers," Biochimie, vol. 92, no. 3, pp. 292-306, 2010.

[25] I. Bièche, C. Narjoz, T. Asselah et al., "Reverse transcriptasePCR quantification of mRNA levels from cytochrome (CYP) 1 , CYP2 and CYP3 families in 22 different human tissues," Pharmacogenetics and Genomics, vol. 17, no. 9, pp. 731-742, 2007.

[26] J. A. DeLoia, W. C. Zamboni, J. M. Jones, S. Strychor, J. L. Kelley, and H. H. Gallion, "Expression and activity of taxane-metobolizing enzymes in ovarian tumors," Gynecologic Oncology, vol. 108, no. 2, pp. 355-360, 2008.

[27] A. Gaedigk, D. W. Baker, R. A. Totah et al., "Variability of CYP2J2 expression in human fetal tissues," Journal of Pharmacology and Experimental Therapeutics, vol. 319, no. 2, pp. 523-532, 2006.

[28] J. G. Jiang, C. L. Chen, J. W. Card et al., "Cytochrome P450 2J2 promotes the neoplastic phenotype of carcinoma cells and is up-regulated in human tumors," Cancer Research, vol. 65, no. 11, pp. 4707-4715, 2005.

[29] A. E. Enayetallah, R. A. French, and D. F. Grant, "Distribution of soluble epoxide hydrolase, cytochrome P450 2C8, 2C9 and 2J2 in human malignant neoplasms," Journal of Molecular Histology, vol. 37, no. 3-4, pp. 133-141, 2006.

[30] R. S. Freedman, E. Wang, S. Voiculescu et al., "Comparative analysis of peritoneum and tumor eicosanoids and pathways in advanced ovarian cancer," Clinical Cancer Research, vol. 13, no. 19, pp. 5736-5744, 2007.

[31] C. Chen, X. Wei, X. Rao et al., "Cytochrome P450 2J2 is highly expressed in hematologic malignant diseases and promotes tumor cell growth," Journal of Pharmacology and Experimental Therapeutics, vol. 336, no. 2, pp. 344-355, 2011.

[32] J. P. Vanden Heuvel and J. M. Peters, "Peroxisome proliferatoractivated receptors," in Comprehensive Toxicology (Cellular and Molecular Toxicology), C. A. McQueen, J. Bond, K. Ramos et al., Eds., vol. 2, pp. 145-167, Elsevier, New York, NY, USA, 2010, http://www.knovel.com/web/portal/browse/display? EXT_KNOVEL_DISPLAY_bookid=3459\&VerticalID $=0$.

[33] Y. Chen, A. R. Jimenez, and J. D. Medh, "Identification and regulation of novel PPAR- $\gamma$ splice variants in human THP-1 macrophages," Biochimica et Biophysica Acta, vol. 1759, no. 12, pp. 32-43, 2006.

[34] B. P. Kota, T. H. W. Huang, and B. D. Roufogalis, "An overview on biological mechanisms of PPARs," Pharmacological Research, vol. 51, no. 2, pp. 85-94, 2005.

[35] K. A. Burns and J. P. Vanden Heuvel, "Modulation of PPAR activity via phosphorylation," Biochimica et Biophysica Acta, vol. 1771, no. 8, pp. 952-960, 2007.

[36] W. D. Rees, C. J. McNeil, and C. A. Maloney, "The roles of PPARs in the fetal origins of metabolic health and disease," PPAR Research, vol. 2008, Article ID 459030, 8 pages, 2008.

[37] K. Nadra, S. I. Anghel, E. Joye et al., "Differentiation of trophoblast giant cells and their metabolic functions are dependent on peroxisome proliferator-activated receptor $\beta / \delta$," Molecular and Cellular Biology, vol. 26, no. 8, pp. 3266-3281, 2006.
[38] Y. Barak, M. C. Nelson, E. S. Ong et al., "PPAR $\gamma$ is required for placental, cardiac, and adipose tissue development," Molecular Cell, vol. 4, no. 4, pp. 585-595, 1999.

[39] N. Kubota, Y. Terauchi, H. Miki et al., "PPAR $\gamma$ mediates high-fat diet-induced adipocyte hypertrophy and insulin resistance," Molecular Cell, vol. 4, no. 4, pp. 597-609, 1999.

[40] L. Michalik and W. Wahli, "Peroxisome proliferator-activated receptors (PPARs) in skin health, repair and disease," Biochimica et Biophysica Acta, vol. 1771, no. 8, pp. 991-998, 2007.

[41] M. G. Hall, L. Quignodon, and B. Desvergne, "Peroxisome proliferator-activated receptor $\beta / \delta$ in the brain: facts and hypothesis," PPAR Research, vol. 2008, Article ID 780452, 10 pages, 2008.

[42] C. Huin, L. Corriveau, A. Bianchi et al., "Differential expression of peroxisome proliferator-activated receptors (PPARs) in the developing human fetal digestive tract," Journal of Histochemistry and Cytochemistry, vol. 48, no. 5, pp. 603-611, 2000.

[43] T. Fournier, V. Tsatsaris, K. Handschuh, and D. Evain-Brion, "PPARs and the placenta," Placenta, vol. 28, no. 2-3, pp. 6576, 2007.

[44] B. D. Abbott, C. R. Wood, A. M. Watkins, K. P. Das, and C. S. Lau, "Peroxisome proliferator-activated receptors alpha, beta, and gamma mRNA and protein expression in human fetal tissues," PPAR Research, vol. 2010, Article ID 690907, 19 pages, 2010.

[45] M. Rakhshandehroo, B. Knoch, M. Müller, and S. Kersten, "Peroxisome proliferator-activated receptor alpha target genes," PPAR Research, vol. 2010, Article ID 612089, 20 pages, 2010.

[46] L. Richert, G. Tuschl, C. Viollon-Abadie et al., "Species differences in the response of liver drug-metabolizing enzymes to (S)-4-O-tolylsulfanyl-2-(4-trifluormethyl-phenoxy)-butyric acid (EMD 392949) in vivo and in vitro," Drug Metabolism and Disposition, vol. 36, no. 4, pp. 702-714, 2008.

[47] Z. Shaban, M. Soliman, S. El-Shazly et al., "AhR and PPAR $\alpha$ : antagonistic effects on CYP2B and CYP3A, and additive inhibitory effects on CYP2C11," Xenobiotica, vol. 35, no. 1, pp. 51-68, 2005.

[48] R. Večeřa, A. Zachařová, J. Orolin, J. Strojil, N. Škottová, and P. Anzenbacher, "Fenofibrate-induced decrease of expression of CYP2C11 and CYP2C6 in rat," Biopharmaceutics \& Drug Disposition, vol. 32, no. 8, pp. 482-487, 2011.

[49] X. Zhao and L. Y. Li, "PPAR-alpha agonist fenofibrate induces renal CYP enzymes and reduces blood pressure and glomerular hypertrophy in Zucker diabetic fatty rats," American Journal of Nephrology, vol. 28, no. 4, pp. 598-606, 2008.

[50] A. Pozzi, M. R. Ibanez, A. E. Gatica et al., "Peroxisomal proliferator-activated receptor- $\alpha$-dependent inhibition of endothelial cell proliferation and tumorigenesis," The Journal of Biological Chemistry, vol. 282, no. 24, pp. 17685-17695, 2007.

[51] J. A. Wray, M. C. Sugden, D. C. Zeldin et al., "The epoxygenases CYP2J2 activates the nuclear receptor PPAR $\alpha$ in vitro and in vivo," PLoS ONE, vol. 4, no. 10, Article ID e7421, 2009.

[52] V. Y. Ng, Y. Huang, L. M. Reddy, J. R. Falck, E. T. Lin, and D. L. Kroetz, "Cytochrome P450 eicosanoids are activators of peroxisome proliferator-activated receptor $\alpha$," Drug Metabolism and Disposition, vol. 35, no. 7, pp. 1126-1134, 2007.

[53] T. Prueksaritanont, K. M. Richards, Y. Qiu et al., "Comparative effects of fibrates on drug metabolizing enzymes in human hepatocytes," Pharmaceutical Research, vol. 22, no. 1, pp. 7178,2005 . 

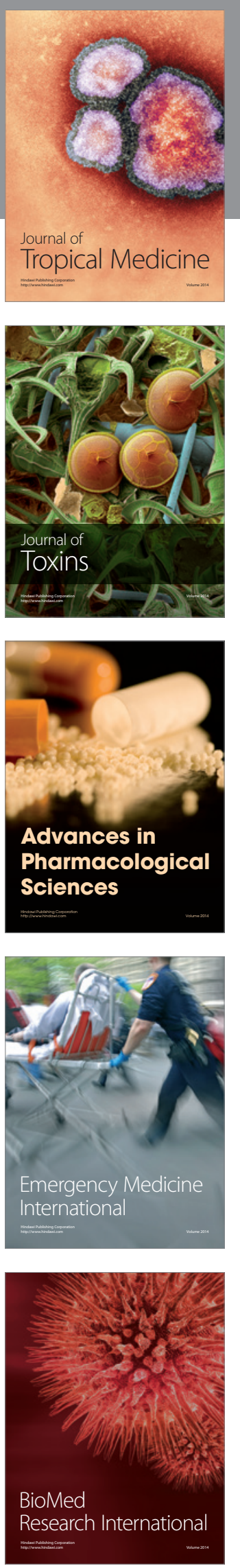
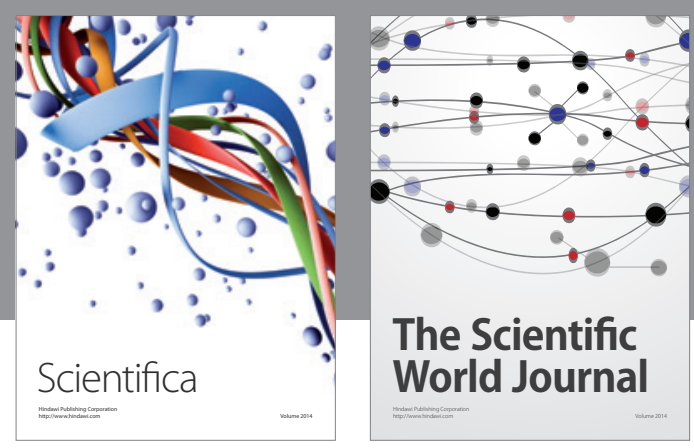

The Scientific World Journal
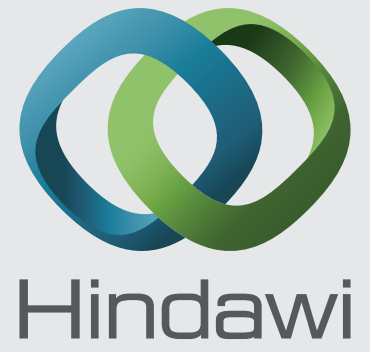

Submit your manuscripts at

http://www.hindawi.com
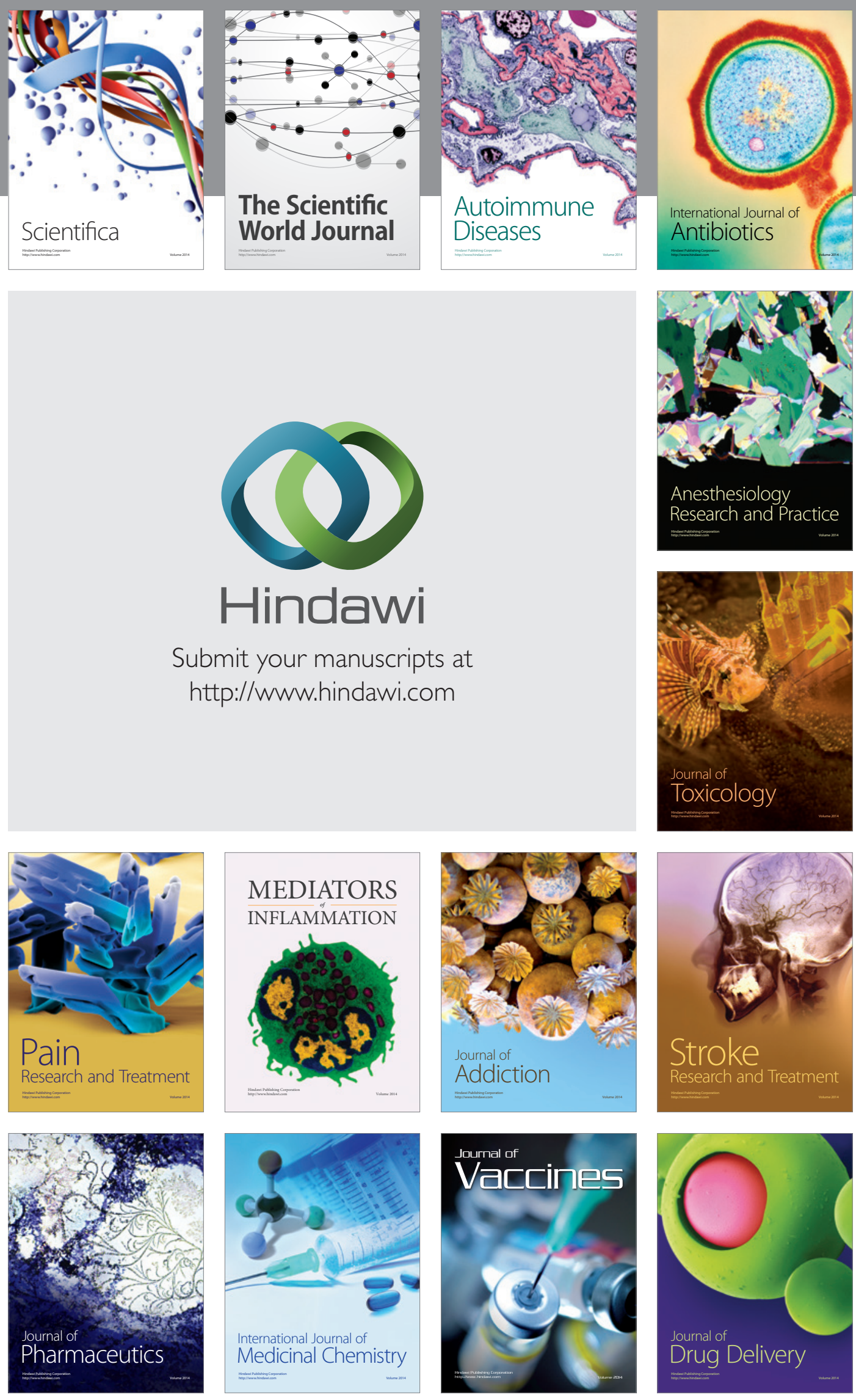